\title{
Integrating stages of change models to cast new vision on interventions to improve global retinoblastoma and childhood cancer outcomes
}

\author{
Meaghann S Weaver ${ }^{1,2^{*}}$, Christina L Heminger ${ }^{2}$ and Catherine G Lam ${ }^{1,3}$
}

\begin{abstract}
Background: Retinoblastoma, the most common intraocular tumor globally, represents a curable cancer when diagnosed early and treated promptly. Delay to diagnosis, lag time prior to treatment initiation, and abandonment of treatment including upfront treatment refusal, represent stark causes of high retinoblastoma mortality rates in low- and middle- income settings, particularly regions in Africa. While a health delivery-based approach has been a historic focus of retinoblastoma treatments globally and is essential to quality care, this is necessary but not adequate. Retinoblastoma is a compelling disease model to illustrate the potential insights afforded in theory-informed approaches to improve outcomes that integrate public health and oncology perspectives, prioritizing both health service delivery and social efficacy for cure.
\end{abstract}

Discussion: Given that barriers to appropriate and timely diagnosis and treatment represent main contributors to mortality in children with retinoblastoma in resource-limited settings such as certain areas in Africa, an important priority is to overcome barriers to cure that may be predominantly socially influenced, alongside health delivery-based improvements. While Stages of Change models have been effectively utilized in cancer screening programs within settings of economic and cultural barriers, this application of health behavior theory has been limited to cancer screening rather than a comprehensive framework for treatment completion. Using retinoblastoma as a case example, we propose applying stage-based intervention models in critical stages of care, such as the Precaution Adoption Process Model to decrease delay to diagnosis and a Transtheoretical Model to increase treatment completion rates in resource-limited settings.

Summary: Stage-based theories recognize that improved cure and survival outcomes will require supportive strategies to progress households, communities, and social and economic institutions from being unaware and unengaged to committed and sustained in their respective roles. Applying a stage-based model lens to programmatic interventions in resource-limited settings has potential for visible improvement in outcomes for children with retinoblastoma and other cancers.

Keywords: Retinoblastoma, Pediatric oncology, Stages of change model, Resource-limited settings, Interventions, Diagnostic barriers, Treatment barriers, Social efficacy

\footnotetext{
* Correspondence: Meaghann.Weaver@StJude.org

'Department of Oncology, St. Jude Children's Research Hospital, 262 Danny

Thomas Place, Memphis, Tennessee 38105, USA

${ }^{2}$ Milken Institute School of Public Health, The George Washington University,

2175 K Street NW, Washington, District of Columbia 20037, USA

Full list of author information is available at the end of the article
} 


\section{Background}

\section{Global priority based on incidence}

Retinoblastoma represents the most common pediatric intraocular cancer with the greatest disease burden in populations with high birth rates. Across the globe, there are 9,000 new diagnoses of retinoblastoma estimated annually, or approximately one case per 15000 live births, with the majority in resource-limited settings [1]. Hospital- based studies in India suggest that this intraocular cancer may comprise up to $10-15 \%$ of all diagnosed childhood cancers in parts of India, in contrast to most developed settings where it accounts for less than $5 \%$ of pediatric cancers [2]. The varying reported incidence of retinoblastoma within countries likely reflects reporting mechanisms more than true incidence difference $[3,4]$. Retinoblastoma has been reported as the most frequent solid tumor diagnosis in Mexico after central nervous system neoplasms [5] and in northern Nigeria, retinoblastoma is documented as the most common childhood malignancy overall, accounting for almost one-third of all pediatric oncology cases [6]. Retinoblastoma has been documented among the top three childhood cancers diagnosed in Tanzania, Ghana, the Congo, and Kenya and as the fourth most common in Senegal [7-11]. The documented recognition of retinoblastoma in low- and middle-income settings (LMIS) is believed to underrepresent the actual number of cases $[9,12]$.

Among areas with lower overall detection of childhood cancers, there is an apparent high incidence in advanced stage retinoblastoma being reported [13]. This eye tumor progresses through signs that can be relatively subtle, such as strabismus (abnormal eye alignment often resulting in a squint), to leukocoria (white light reflex, which can be readily recognized by alert family and community members), to more advanced orbital inflammation, proptosis (orbital bulge) and bulky protruding extraocular masses literally staring at an observer both in community and clinical settings, accompanied by distant disease spread [14]. Retinoblastoma may therefore be more amenable to reporting in low- and middle-income settings globally as compared with other childhood oncologic diagnoses in these same settings that may be more heavily resource- or technology-dependent.

\section{Extent and impact of delay}

Retinoblastoma represents a curable cancer when caught early. Whether the lag time is due to delay in diagnosis or due to delay in treatment initiation (Figure 1), population-based studies reveal extended delays in access to cure in many LMIS. As an example, we explored quantified pediatric retinoblastoma lag times as reported in the continent of Africa through a comprehensive literature review and direct author contact for additional information regarding both published and unpublished data, with data available for 10 countries detailed (Figure 2). Mean time from symptom onset to diagnosis was reported by retrospective chart reviews as 6 months in Nigeria $(n=26)$ [15], 10 months in Tunisia $(n=35)$ [16], 8 months in Tanzania $(n=91)$ [17], and over 24 months in Mali $(n=50)$ [18]. A delay of more than six months from the first clinical sign of retinoblastoma to diagnosis is associated with assured extraocular spread and 70\% mortality [3]. Of the cases of retinoblastoma diagnosed over a fiveyear period in central Africa, over $90 \%$ of the patients presented to the retinoblastoma center after extraocular spread [19]. In Kenya, where the delay from retinoblastoma symptom onset to diagnosis is a mean of 6.8 months, the mortality of retinoblastoma is $73 \%$ [20], which is over 50 times higher than that in Canada (1\%) [21]. Approximately half to three-fourths of children diagnosed with retinoblastoma in Africa die, presumably due to diagnosis at an advanced stage, while 3-5\% of children with retinoblastoma die in the United States and Europe, presumably in part due to earlier diagnosis alongside comprehensive management [3]. While current treatment emphasis in high-income countries focuses on vision-sparing interventions, the priority in LMIS remains the life-saving interventions of prompt diagnosis and treatment. A tri-modal depiction of delay (Figure 3) acknowledges that a conglomeration of health service delivery and social efficacy promotion must be established in the steps from first symptom recognition to diagnosis to urgent treatment initiation [22].

Medical factors interplay with complex and shifting social dynamics. As health delivery systems improve and as medical care advances, the management of retinoblastoma shifts from the basic priority of saving the life of the child with retinoblastoma, to include prioritization of ocular salvage. While the Stages of Change model we detailed here emphasizes early recognition and acceptance of enucleation (a survival priority) that may best apply to late presenting retinoblastoma in resource-limited settings, components and applications of this model may be adapted for other heterogeneous contexts. For instance, in contexts with earlier presentations and additional resources, consideration of the best interests of the child with intraocular disease may warrant weighing the continuum of readiness for intra-arterial or systemic therapy (an ocular salvage priority), and recognizing the perceptions and barriers that may affect uptake of these therapies where appropriate and available. Rather than view theory as a rule equally applicable in all settings, informed application of theory recognizes the unique and complex dimensions of the social and medical decisional continuums.

\section{Barriers to diagnosis}

Health service delivery barriers to earlier diagnosis in LMIS include lack of universal health insurance for 


\section{Overall lag time}

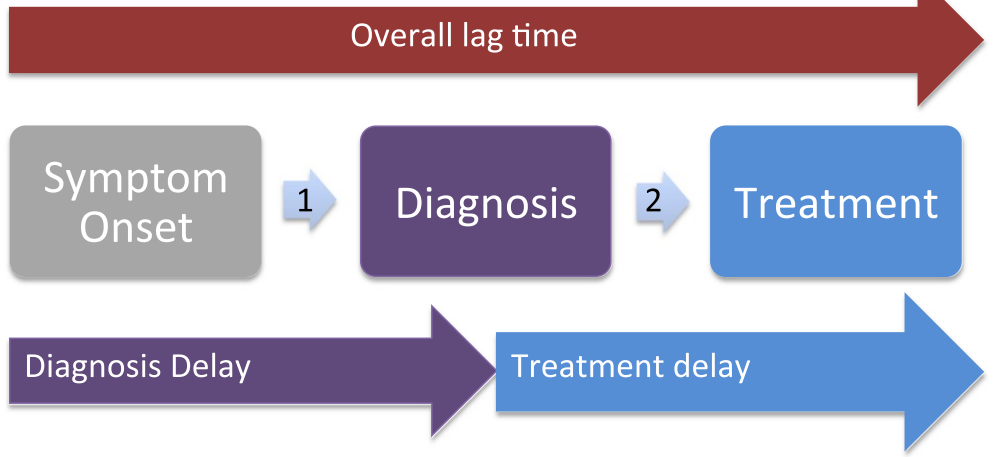

Figure 1 Delineating lag time. Delineating total lag time (red) prior to initiation of curative therapy as composed of delay to diagnosis (purple) and delay to treatment initiation (blue).

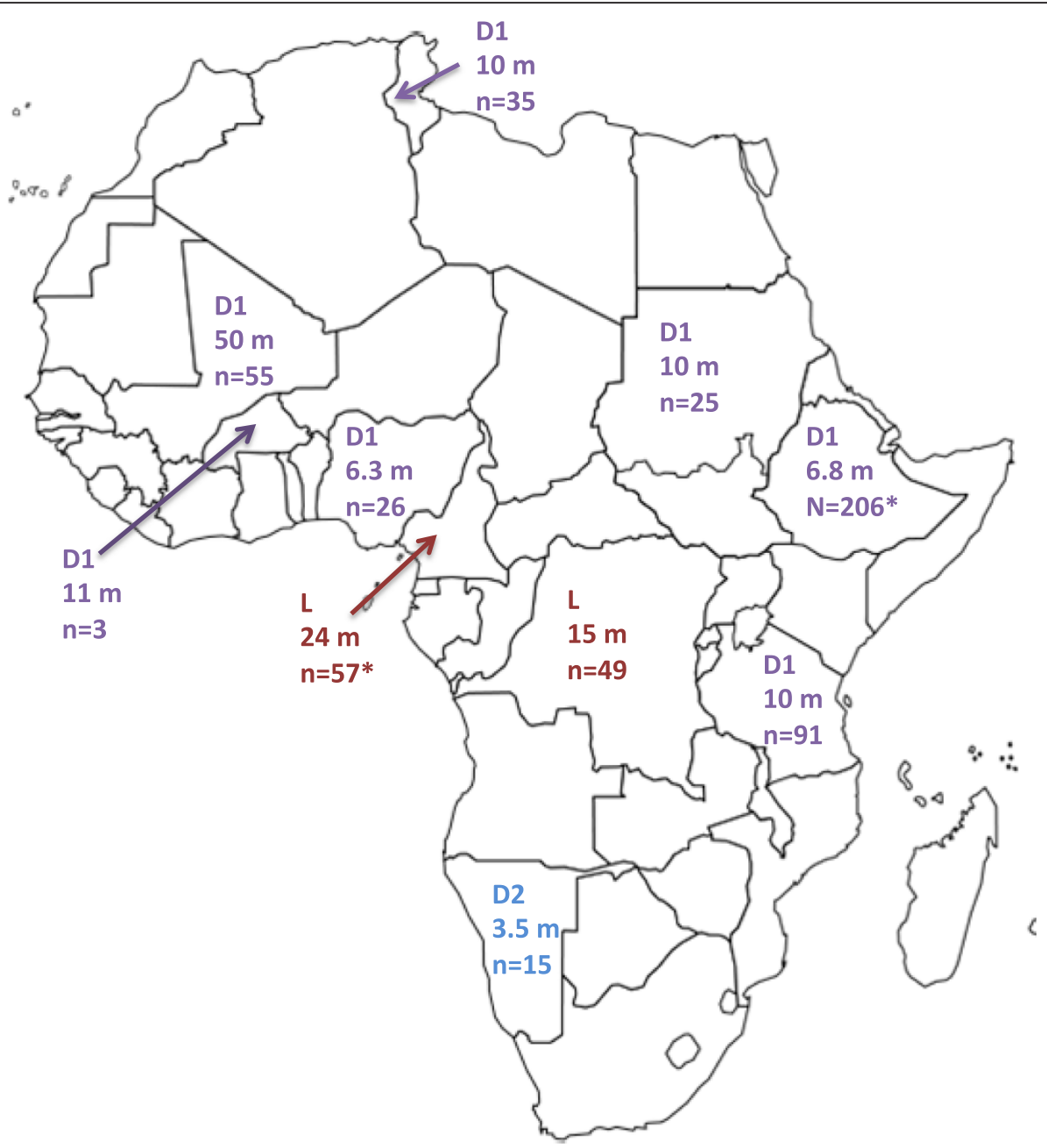

Figure 2 Duration (in months) of delays to retinoblastoma treatment in Africa. $L=$ Delay from symptom to treatment, D1 = Delay from symptom onset to diagnosis, D2 = Delay from diagnosis to treatment initiation. ${ }^{*}=$ month duration obtained through personal communication with authors and included with authors' kind permission (unpublished data). Cameroon $L=24$ months, $n=57$ (Kagmeni2013*) [23]. Congo $L=24$ months, $n=49$ (Lukusa2012) [9]. Nigeria D1 = 6.3 months, $n=26$ (Bekibele2009) [24]. Tanzania D1 = 10 months, $n=91$ (Bowman2008) [17]. Mali $D 1=50$ months, $n=55$ (Boubacar2010) [18]. Tunisia D1 $=10$ months, $n=35$ (Frikha2009) [16]. Namibia D2 $=3.5$ months, $n=15$ (Wessels1996) [25]. Sudan D1 = 10 months, $n=25$ (Ali201 1) [26]. Burkina Faso, D1 = 11 months, $\mathrm{n}=3$ (Nikiema2009) [27]. Kenya D1 =6.8 months, $\mathrm{n}=206$ (Nyamori2012*) [20]. 


Delay in Seeking and
Reaching Care
- Failure to recognize
symptoms (white pupil,
bulging eye)
- Lack of encouragement
from social support to
seek care
- Lack of child care for
other children
- Prohibitive distance
between home and
provider (time away
from work or home
responsibilities and
transport cost)
- No roads or poor
upkeep or low security
of roads

Delay in Decision to Seek
and in Receipt of
Diagnosis
- Lack of ability of care-
provider to make or
pursue diagnostic
decisions
- Lack of awareness of
existing services
- Reluctance to seek
diagnosis because of
cultural constraints
- Fear of ill-treatment or
judgment at medical
facility
- Burden of time waiting
to be seen by health
provider
- Lack of or limited access
to trained personnel or
diagnostic resources

Delay in Receipt of
Appropriate Treatment
- Lack of trained
personnel
- Weak referral system
(including
communication and
transportation)
- Fragmented inter-
disciplinary team
dynamics
- Delayed access to
pathology
- Lack facilities, supplies
or medicines
- Diminished partnership
between patient and
care team
- Lack of psychosocial
support for patient

Figure 3 Tri-lineage model of delay with description of possible causation. non-communicable diseases, missing links in multidisciplinary inclusion, constraints in procurements of diagnostic supplies, and inefficiencies within the referral system [24]. Local community health workers or general care providers may not have the referring mechanism readily in place to expedite a family's access to diagnosis. Social barriers to receipt of a diagnosis include a myriad of educational, cultural, and economic influences. Lack of parental education and low awareness of the signs and symptoms of retinoblastoma can delay families from seeking medical attention [28]. Parents may fear judgment from the medical team if the retinoblastoma symptoms have progressed to the point of disfiguration prior to presentation to care. Even when a family does recognize the signs of retinoblastoma, some families may believe eye cancer is incurable and therefore select not to seek medical care (cancer fatalism) [10]. Chart assessments of causes for delay to retinoblastoma diagnosis in LMIS describe parental reliance on traditional healers or prayer camps for initial treatment due to available access and cultural prioritization $[9,29,30]$, as belief-system has clear impact on care seeking [31,32]. Conflicting priorities, to include survival priorities such as food or school fees for other siblings, may realistically serve as barriers to pursuit of a diagnosis. Parents may not be able to fund diagnostic procedures. Parents may also not have means of transport to medical centers due to prohibitive travel time, transportation fees, or lack of reliable or safe roads. Regional conflict and political strife risk disrupting vital health services and supply chains, which urges attentiveness to the needs of children with chronic conditions during times of acute conflict [33].

\section{Barriers to treatment initiation and completion}

Despite receipt of a retinoblastoma diagnosis, the child's life is jeopardized if necessary treatment is delayed [34]. Health service delivery barriers to earlier treatment initiation in LMIS include lack of cost coverage for curativedirected treatments; shortage of personnel; fragmented or delayed hand-offs between multi-disciplinary team members such as general providers, pathologists, oncologists, surgeons; constraints in access to surgical supplies; and medication shortages [24]. Even if the health delivery system was fluid and efficient, the cultural context of partnership, education, and enablement between families and providers remains critical. A family's understanding of the treatment plan and trust in the health team remains a vital component to treatment efficacy and psychosocial wellness [35]. Refusal of enucleation (removal of the eye globe) has been documented as a main obstacle to cure in up to $40 \%$ of all patients diagnosed with retinoblastoma in lowincome settings [36]. Families in some LMIS may reject enucleation as curative treatment because of actual or perceived social stigma or poor understanding of the high quality of life possible after unilateral enucleation [4]. A retrospective review of enucleation refusal from Nigeria reported $>10 \%(3 / 26)$ upfront enucleation refusal rate and $42 \%$ abandonment rate prior to enculeation (11/23) [24]. Investigation of attitudes regarding blindness in Africa reveal continued prevalence of stigma attached to eye loss, particularly in rural communities $[37,38]$. Furthermore, 
delays during treatment and treatment abandonment may adversely affect a dominant proportion of patients in resource-limited settings [14,34,39]. Ultimately, delays in diagnosis and treatment that result in more advanced, extraocular disease are unfortunately associated with requirements for more intensive therapy and expertise with greater demand for resources, higher morbidity and less chance of cure and survival. Children diagnosed early with disease well-confined within the eye, however, can often be saved with simpler surgical enucleation alone, thus addressing barriers to timely treatment have great potential to save resources as well as patients' lives.

\section{Purpose statement}

Viewing pediatric oncology interventions, such as retinoblastoma diagnosis and treatment interventions, through a comprehensive public health lens provides opportunity for new insights. A public health model (Table 1) can be applied to guide all programmatic steps from defining the problem through to intervention planning, implementation, and evaluation [40]:

During the definition phase, a public health approach surveys community awareness regarding retinoblastoma, attitudes regarding cancer susceptibility and severity, and extent of blindness stigma. The definition phase necessarily investigates baseline cancer knowledge and referral trends of local health care providers [5]. The public health model then assesses available local resources and analyzes barriers to patient and provider efficacy. During the planning phase, a public health approach prioritizes

\section{Table 1 Public health approach to retinoblastoma}

\begin{tabular}{ll}
\hline Programmatic phase & Public health approach \\
\hline Definition phase & Survey community awareness regarding \\
retinoblastoma [41] & Monitor baseline knowledge of healthcare \\
& providers [5] \\
- & Assess attitudes regarding cancer susceptibility \\
& and severity \\
- & Determine extent of blindness stigma within \\
& community \\
- & Assess available local resources \\
- & Determine barriers to patient and provider \\
& efficacy \\
- & Prioritize partnerships and resources that would \\
& be effective within this cultural and cost-context \\
- & Prepare educational intervention for healthcare \\
& provider referral sources \\
- Frame the strategies and materials within local & context \\
- Implement cancer curricular for healthcare & providers \\
- & Continually improve quality via feedback loops \\
Evaluation & during each stage \\
\hline Implementation phase phase &
\end{tabular}

partnerships and resources that would be effective within this cultural and cost-context. Development of educational resources for health care providers occurs in the planning phase. During implementation, a public health approach frames the strategies and materials utilized. Whereas success in strictly medical models is traditionally defined through calculation of inputs, outputs, and outcomes obtained at the conclusion of a project, a public health model encourage continuous quality improvement via feedback loops throughout the iterative stages of design, planning, implementation, and evaluation.

\section{Discussion}

Innovation of stages of change-based approach to retinoblastoma

While the innovative emphasis of this paper is to target Stages of Change models for earlier retinoblastoma diagnosis and treatment, effective intervention programs would be blind to reality to not concurrently prioritize health delivery improvements such as creation of multidisciplinary care teams, central pathology review, referral system logistics strengthening, uniform treatment protocols, reliable access to supplies and medications, cost coverage for treatment, and provision of transportation and housing. Establishment of twinning (collaboration and support partnership) programs in Guatemala and Jordan and development of integrated multidisciplinary services in Argentina and India have provided documented improvements in retinoblastoma treatment outcomes with health deliverytargeted interventions [4]. Availability of appropriate and adequate treatment is a necessary step in overcoming treatment delay.

The ability of public health interventions to impact retinoblastoma outcomes through community awareness has been well-documented [41]. A campaign linking retinoblastoma education to a national campaign in Honduras decreased median time from symptom to diagnosis from 7.2 months to 5.5 months and decreased the proportion of extraocular cases at time of presentation from $73 \%$ to $35 \%$ [42]. An early diagnosis campaign in Brazil trained public school teachers and community health workers to recognize the symptoms of retinoblastoma, resulting in decreased extraocular disease at time of presentation from $56 \%$ to $<10 \%$ in less than 20 years [4]. Within the context of the Stages of Change Models, these community awareness approaches are viewed as necessary external influences, mediating the family's ultimate readiness for treatment.

Even the most efficient of health delivery improvements and community awareness campaigns do not manifest effects on survival outcomes if the family remains undecided about seeking medical attention for leukocoria or if the family refuses enucleation. Stagebased intervention models recognize that decisions to 
pursue a diagnosis and engage in treatment are complex and involve a variety of motivations, knowledge levels, and readiness. Stage-based interventions target supportive behavioral strategies to help families prepare for the next decisional stage in diagnosis and treatment. Stages of Change models have been utilized effectively in breast, skin, colorectal, and cervical cancer screening decisional interventions to include settings of economic and cultural barriers $[43,44]$. Although utilized in cancer screening, stage-based models have not been comprehensively applied to pediatric oncology interventions from the initial programmatic design through implementation and evaluation. A recent study describing pediatric retinoblastoma treatment completion in India documented family unwillingness to allow enucleation $(20 \%, \mathrm{n}=16)$ as the second most common cause for treatment failure and thereby targeted the essential role of family-directed support interventions for treatment completion [39]. This study strategically timed interventions such as placing posters of patients successfully treated for retinoblastoma (with emphasis on the cosmetic outcome of prostheses) in the clinic area, creating a parent group with presence of parent experts (parents of child survivors of retinoblastoma), and intensifying family counseling sessions from time of initial clinic contact. These interventions were associated with resultant steady decline in treatment abandonment rates from $71 \%$ in 2008 to $17 \%$ in $2011(\mathrm{P}=0.01)$ [39].

Facing system and social barriers, families should not receive blame for delay to diagnosis, delay to treatment initiation, or abandonment of treatment. At the same time, these real barriers reveal opportunities to attentively support and move families through the complex stages of readiness for diagnosis and receipt of treatment.

\section{Delay in time to diagnosis: method for precaution adoption process model interventions}

Leukocoria is the most common initial sign of retinoblastoma. Retinoblastoma remains intraocular and curable for the first 3-6 months after the first sign of leukocoria, making this a most urgent time for diagnosis before retinoblastoma spreads beyond the eye [28]. Because parents are often the first to note the ocular sign of leukocoria [45], retinoblastoma symptom awareness must prioritize family members. The Precaution Adoption Processes Model (PAPM) seeks to identify the stages involved when people commence health-protective behaviors for a dichotomous action such as seeking diagnosis for a symptom. PAPM as illustrated here presumes presence of some basic infrastructure including that to diagnosis retinoblastoma, and which in our example also included those such as well child checks, patient navigators, psychosocial support services, and prosthetic eye interventions. PAPM recognizes the factors that move people from one stage to the next, namely lack of awareness of the first symptom to the action of obtaining a diagnosis and, ultimately, the option for an individual to "exit" the model through a refusal to act (in this case, obtain a diagnosis) and terminate stage change. The barriers impeding progress toward diagnosis are targeted specifically to the decisional stage the family has reached. While many patients in truly low-income settings may present with metastatic disease beyond targeted interventions' reach, recognition of variability in patients' presentation within a given setting as well as promotion of efforts to address stage-specific barriers as a community can in turn galvanize the resources and social shifts necessary. Applied in a setting with appropriate resources, PAPM has potential to systematically inform development of interventions to decrease the time interval from retinoblastoma symptom onset to diagnosis by programmatically partnering with families accordingly to their expressed needs in each decisional stage leading to diagnosis (Figure 4).

\section{Delay in time to treatment: method for transtheoretical model interventions}

The Transtheoretical Model (TTM) seeks to identify the stages involved when people commence health-protective behaviors and recognizes the factors that move people from one stage to the next, ranging from Precontemplation where the family is either unaware or unengaged in making a behavioral change, to Maintenance, where Action is sustained over a period of time. The model allows for relapse and re-entry in recognizing that behavior change is complex and non-linear; additionally, the theory authors have identified processes of change that exemplify movement from one stage to another (Figure 5).

A very large proportion of patients in low-income settings present with extraocular disease, whereby decisions may involve palliation versus treatment secondary to the realities of limited resources, in which case TTM may not be readily applied for this unique context. In the particular setting where minimum resources are available (medical team and social support) and where acceptance of enucleation versus ocular salvage represents the key defining step, TTM may then be considered as an applicable theory. Using TTM, a family can be described along a series of temporal dimensions in decisional acceptance and treatment readiness with the timeline redefined in retinoblastoma due to urgency (Table 2).

Interventions at each stage primarily require creativity and commitment of planners without necessarily requiring cost-intensive resources. Examples are outlined further below, with recognition that precise applications of these social efficacy promotion efforts may vary depending on the maturity of the other health service delivery interventions and context of the local health system. 


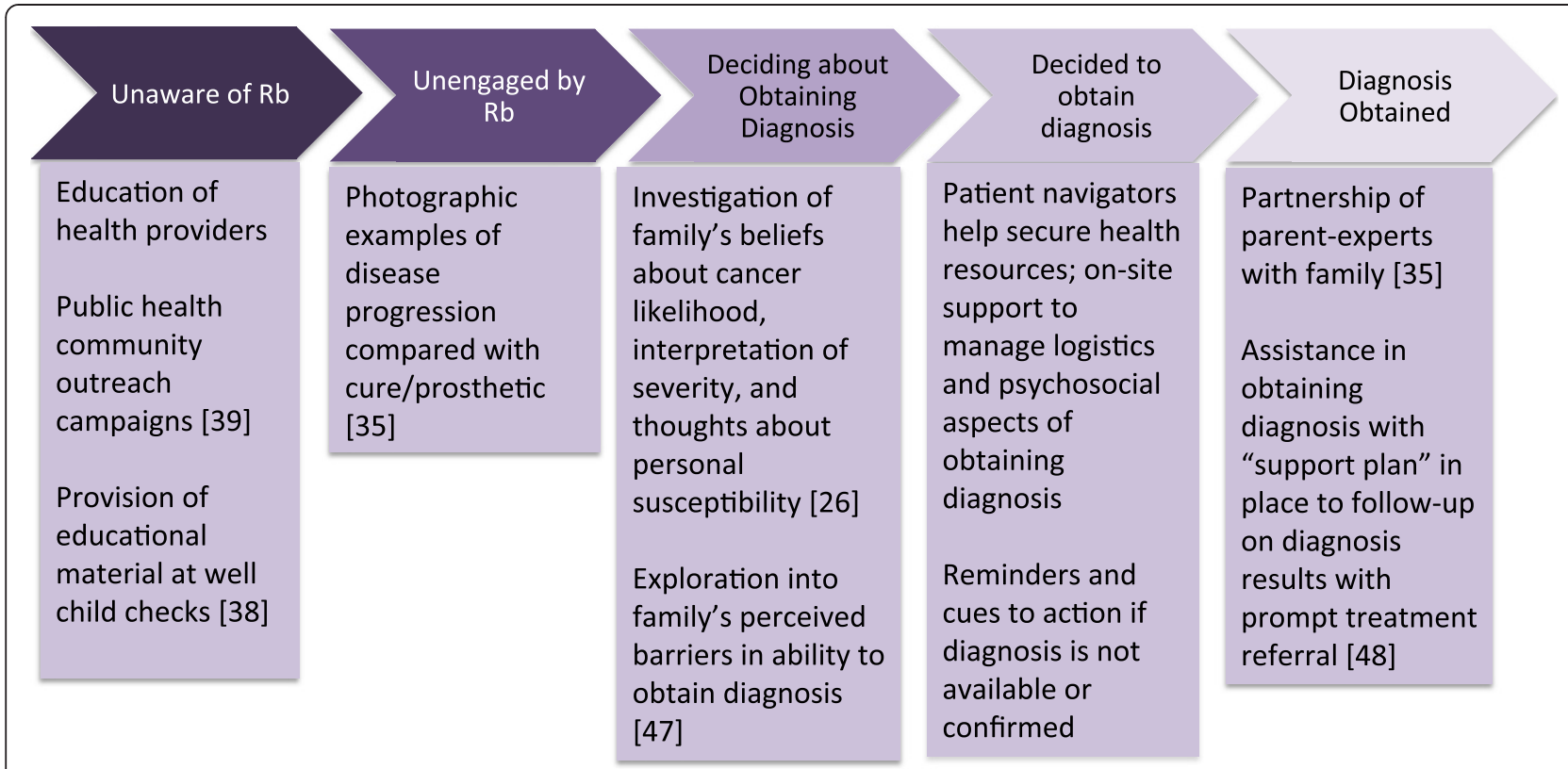

Individualized counseling for families with engagement of community leaders and advocates to address specific needs

Figure 4 Precaution adoption process model applied to "social interventions" for earlier diagnosis of retinoblastoma in LMIS.

For transition from precontemplation to contemplation: This intervention engages with the family and patient with information about the urgent need to start treatment and provides personal information about the risks of not receiving treatment. As part of the consciousness-raising process, there is personalized education on cure and the consequences of no action. As part of the dramatic relief process, there is opportunity for personal testimonies from parent groups and pictures of orbital prosthesis cosmetic results shared with parents. Awareness raising interventions should continually improve upon the local quality of orbital prostheses through local partnerships with those experienced in sizing and placing orbital prosthesis with minimal infection risks. As part of environmental reevaluation, parent networks model the potential for families to envision themselves serving as positive role models for others.

For transition from contemplation to preparation: There is motivation and encouragement of the family to set goals and make specific plans through one-on-one sessions with the health team to include social workers and psychologists. As part of self-reevaluation, there are opportunities for meetings with parents of retinoblastoma survivors present to discuss the parental-image and community-image and self-image of the child after enucleation. This provides opportunity for value clarification and recognition of a successful life while visually impaired. "Family experts" (families who have a child retinoblastoma survivor member) can be available to discuss overcoming acceptance barriers such as blindness stigma and fear of cancer diagnosis.

For transition from preparation to action: The health team helps the family to create and implement specific action plans for treatment start and to set realistic goals in terms of surgical outcome, and side effects of chemotherapy or radiation therapy if needed. Team members involved in psychosocial health of the family or Child Life teams, where available, become increasingly involved to support the patient with age-appropriate medical interpretations of events (use of dolls to model what the eye bandage will look, self-expression activities, and ageappropriate coping strategies).

For transition from action to treatment: Social support and feedback are emphasized. Liberation, the belief that treatment is attainable and the commitment to act on that belief, is increasingly emphasized with family support sessions. For reinforcement management, therapeutic relationships with social workers and overt reinforcements for families to attend medical appointments may help actualize verbal commitment to treatment. This stage may introduce opportunities for group participation in projects to promote rights/services for cancer patients 


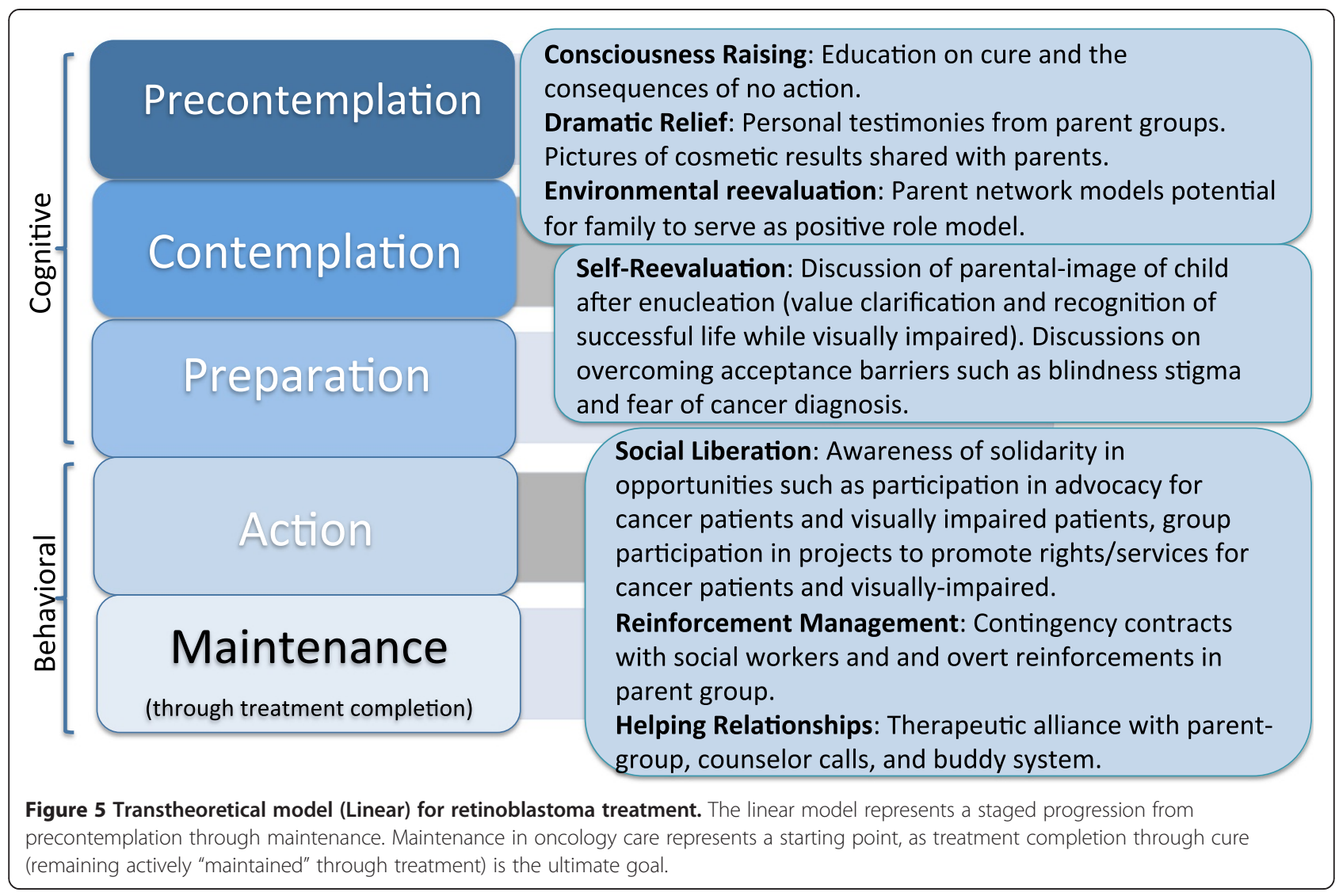

and visually-impaired. This transition relies on helping relationships based on therapeutic alliances whether with parent support groups, counselor telephone calls, and/or buddy systems among family networks. The maintained progression through treatment completion is an essential time to prevent abandonment of therapy. There should be continued social support, assistance with problem solving, and intervention plans in place for missed appointments or delays in care. Supporting families at this stage require creativity and resourcefulness to overcome social, transportation, educational, and financial barriers to treatment completion. This stage emphasizes reminder systems and performance-support tools, which may involve a written calendar, text messaging reminder cues for appointments, or home visits. Effective adherence data tracking under the supervision of staff trained in adherence interventions allows for monitoring and recognition of adherence.

Table 2 Transtheoretical model's stages of change

\begin{tabular}{ll}
\hline Stage of change & Proposed definition \\
\hline Precontemplation & Family has not started treatment and does not intend to start treatment in _ Transition emphasis: acknowledgement of urgent need \\
& Family intends to start treatment but is in a "behavioral procrastination" stage without plan in place to start treatment \\
Contemplation & - Transition emphasis: goal setting with focus on tangible plans to obtain goals \\
Preparation & - Transition emphasis: Establishment of specific steps to action \\
& Family has made specific modifications to their lifestyles in preparation to start treatment \\
Action & - Transition emphasis: Community support and partnership \\
Maintenance & Family is actively in treatment and with intention to continue treatment \\
& - Transition emphasis: Assistance with problem solving and interventions in place to support family through treatment completion
\end{tabular}




\section{Family-efficacy and decisional-balance}

Progression between stages of readiness for treatment initiation is not always lived out as a linear process and may involve regression to a prior stage or abandonment during a stage (Figure 6) [46]. Elements that can modulate the non-linearity of this process include family efficacy, or a family's judgment regarding one's ability to perform a behavior (in this case, engagement in treatment) as required to achieve a certain outcome (cure). Decisional balance, defined as the perceived benefits and perceived barriers affecting health decisions, whether financial, psychological, social, or physical, is also dynamic. The interdisciplinary care team should therefore frequently survey the family's sense of efficacy and decisional balance to proactively intervene to promote healthy stage progression.

\section{Adaptation of proposed models}

Each theory or model, ranging from social determinant of health models to health behavior theories to Stages of Change models, should be continually assessed and tailored for optimized application in order to achieve real-world results. The most effective approach to retinoblastoma outcomes in a particular setting will be a framework that impacts all agents: health care policies and insurance coverage, visually-impaired services in medical and social institutions, and partnerships among intra-disciplinary care teams, communities, families, and patients. The most appropriate application of theories and models will be a locally-selected, culturally-relevant, pragmatic combination of strengths from a variety of theories that best consider the multiple agents, external factors, and internal influences. The goal is for applied

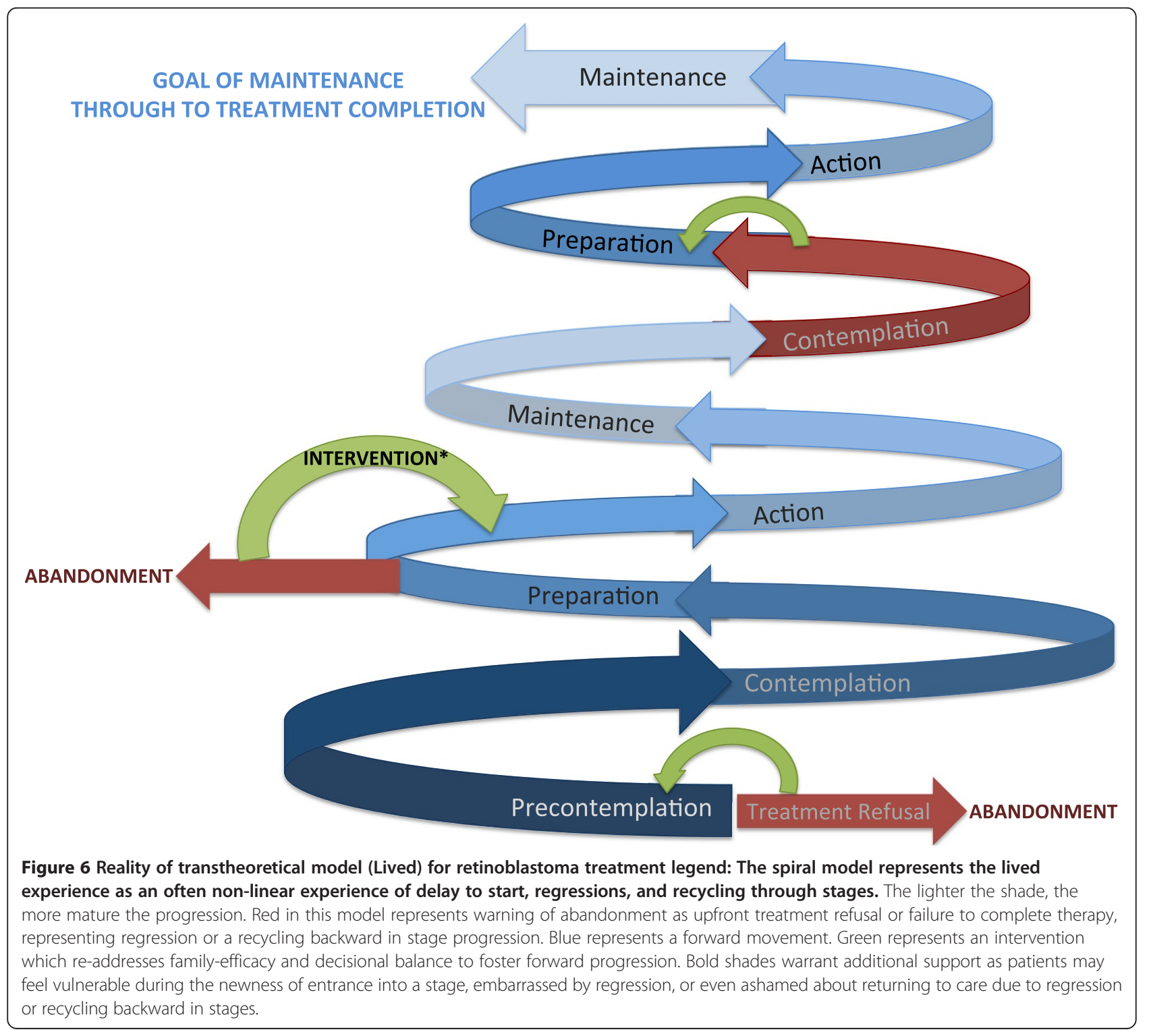


Table 3 Stages of change approach strengths and weaknesses

\begin{tabular}{|c|c|c|}
\hline Approach & Strength & Weakness \\
\hline \multirow{3}{*}{$\begin{array}{l}\text { Precaution Adaption Processes Model } \\
\text { (PAPM) }\end{array}$} & -Dichotomous model, practical for decision-making & -"Decision not to treat" may be viewed as unacceptable \\
\hline & \multirow{2}{*}{$\begin{array}{l}\text {-Incorporates a distinct unawareness stage (versus } \\
\text { unaware OR unengaged) with opportunity for } \\
\text { education }\end{array}$} & $\begin{array}{l}\text {-Emphasis on reading materials/pamphlets may need } \\
\text { to be locally modified to literacy rates }\end{array}$ \\
\hline & & $\begin{array}{l}\text {-Challenge of measuring family's exact stage of } \\
\text { placement }\end{array}$ \\
\hline \multirow[t]{5}{*}{ Transtheoretical Model (TTM) } & $\begin{array}{l}\text {-Removes assumptions about immediate readiness } \\
\text { for behavior }\end{array}$ & \multirow{2}{*}{$\begin{array}{l}\text {-Danger of evolving into a self-help model without } \\
\text { adequate support for change when the external } \\
\text { forces of poverty and conflicting priorities are the } \\
\text { reason for delay }\end{array}$} \\
\hline & -Recognizes different families will be in different stages & \\
\hline & $\begin{array}{l}\text {-Encourages inclusive, appropriately timed motivational } \\
\text { readiness interventions }\end{array}$ & $\begin{array}{l}\text {-Does not always recognize broader social and physical } \\
\text { context }\end{array}$ \\
\hline & \multirow[t]{2}{*}{$\begin{array}{l}\text {-Supports families between decisional stages toward } \\
\text { acceptance }\end{array}$} & $\begin{array}{l}\text {-May unintentionally imply blame on a family, whereas } \\
\text { much of the impetus is a fractured system of care } \\
\text { delivery }\end{array}$ \\
\hline & & $\begin{array}{l}\text {-Common phrases such as "self" efficacy and "self" } \\
\text { realization may not be relevant in settings where } \\
\text { health behaviors and outcomes are communally based }\end{array}$ \\
\hline \multirow{4}{*}{$\begin{array}{l}\text { Decision to not utilize stage- based } \\
\text { model }\end{array}$} & -Potentially streamlined decision-making & \multirow{2}{*}{$\begin{array}{l}\text {-Population characteristics, needs, and values may be } \\
\text { overlooked when community engagement is not } \\
\text { prioritized (available and accessible does not equal } \\
\text { acceptable, appropriate, or equitable) }\end{array}$} \\
\hline & $\begin{array}{l}\text {-Time and resources centralized to making treatment } \\
\text { available and accessible }\end{array}$ & \\
\hline & \multirow[t]{2}{*}{$\begin{array}{l}\text {-With limited funding sources, focuses resources on } \\
\text { specific, measurable biological outcomes such as } \\
\text { diagnostic accuracy and disease response }\end{array}$} & $\begin{array}{l}\text {-Risk imposition of an external "evidence based } \\
\text { approach" which is not taking local evidence and } \\
\text { local experience into consideration to facilitate service } \\
\text { or intervention adoption and sustainability }\end{array}$ \\
\hline & & $\begin{array}{l}\text {-Risk suboptimal allocation and mis-prioritization of } \\
\text { resources toward well-intentioned empiric efforts } \\
\text { that are however poorly aligned with target populations' } \\
\text { current stages of readiness for change }\end{array}$ \\
\hline
\end{tabular}

models to inspire and instill realistic, acceptable, measurable health improvement outcomes [47].

Each theory-based approach can bring particular strengths and potential weaknesses (examples in Table 3) and thus best practice requires adaptation and molding for disease-specific applications. Future clinical studies should consider such theory-informed analysis frameworks in addition to daily practice in contextualizing local evidence, prioritizing frameworks and data-driven actions based on the pertinent dominant stages for particular individuals and patient groups.

\section{Summary: shared vision}

"It is a terrible thing to see and have no vision". Helen Keller

Retinoblastoma is often curable when diagnosed early and treated appropriately, but the prognosis is fatal when diagnosis is delayed and treatment is deferred [4]. Health service delivery-based interventions and community awareness interventions have proven helpful in decreasing lag times and improved survival outcomes, but there remains a high rate of delay in diagnosis, lag time to treatment initiation, and treatment abandonment including refusal in certain LMIS. The reality of health service and social barriers to cure obliges us to avoid placing ill-cast blame on families. Instead, a comprehensive programmatic framework that recognizes the lived context of delay provides opportunity for partnership and efficacy promotion. In striving to improve outcomes globally for curable childhood cancer conditions such as retinoblastoma, opportunity arises to include Stages of Change models for treatment completion, within the reality of lived cultural and cost contexts.

\section{Abbreviations}

LMIS: Low- and middle- income settings; PAPM: Precaution adoption process model; Rb: Retinoblastoma; SOC: Stages of change; TाM: Transtheoretical model.

\section{Competing interests}

The authors declare that they have no competing interests.

\section{Authors' contributions}

All authors contributed extensively to the work presented in this paper. MW, $\mathrm{CH}, \mathrm{CL}$ conceived of the study. $\mathrm{CH}$ participated in figure and table design and provided conceptual advice relevant to public health theory application. MW drafted the manuscript with significant editorial input and content revisions from CL. All authors reviewed the final manuscript. All authors read and approved the final manuscript. 


\section{Acknowledgements}

Alia Zaidi and Raul Ribeiro provided valuable background regarding retinoblastoma interventions globally.

\section{Author details}

'Department of Oncology, St. Jude Children's Research Hospital, 262 Danny Thomas Place, Memphis, Tennessee 38105, USA. ${ }^{2}$ Milken Institute School of Public Health, The George Washington University, 2175 K Street NW, Washington, District of Columbia 20037, USA. ${ }^{3}$ International Outreach Program, St. Jude Children's Research Hospital, 262 Danny Thomas Place, MS 721, Memphis, TN 38105, USA.

Received: 23 December 2013 Accepted: 9 September 2014 Published: 11 September 2014

\section{References}

1. Kivela T: The epidemiological challenge of the most frequent eye cancer: retinoblastoma, an issue of birth and death. Br J Ophthalmol 2009, 93(9):1129-1131.

2. Sachdeva S: Trend of reported cases of retinoblastoma under five hospital based cancer registries. Indian J Cancer 2010, 47(4):473-474.

3. Dimaras H, Kimani K, Dimba EA, Gronsdahl P, White A, Chan HS, Gallie BL: Retinoblastoma. Lancet 2012, 379(9824):1436-1446.

4. Rodriguez-Galindo C, Wilson MW, Chantada G, Fu L, Qaddoumi I, Antoneli C, Leal-Leal C, Sharma T, Barnoya M, Epelman S, Pizzarello L, Kane JR, Barfield R, Merchant TE, Robison LL, Murphree AL, Chevez-Barrios P, Dyer MA, O'Brien J, Ribeiro RC, Hungerford J, Helveston EM, Haik BG, Wilimas J: Retinoblastoma: one world, one vision. Pediatrics 2008, 122(3):e763-770.

5. Leal-Leal CA, Dilliz-Nava H, Flores-Rojo M, Robles-Castro J: First contact physicians and retinoblastoma in Mexico. Pediatr Blood Cancer 2011, 57(7):1109-1112.

6. Ochicha O, Gwarzo AK, Gwarzo D: Pediatric malignancies in Kano, Northern Nigeria. World J Pediatr 2012, 8(3):235-239.

7. Mgaya EM, Kitinya JN: Histopathology of malignant tumours of childhood in Tanzania. East Afr Med J 2000, 77(8):435-439.

8. Welbeck JE, Hesse AA: Pattern of childhood malignancy in Korle Bu Teaching Hospital, Ghana. West Afr J Med 1998, 17(2):81-84.

9. Kazadi Lukusa A, Aloni MN, Kadima-Tshimanga B, Mvitu-Muaka M, Gini Ehungu JL, Ngiyulu R, Ekulu Mfutu P, Budiongo Nzazi A: Retinoblastoma in the democratic republic of congo: 20-year review from a tertiary hospital in kinshasa. J Cancer Epidemiol 2012, 2012:920468.

10. Mostert S, Njuguna F, Kemps L, Strother M, Aluoch L, Buziba G, Kaspers G: Epidemiology of diagnosed childhood cancer in Western Kenya. Arch Dis Child 2012, 97(6):508-512.

11. Ka AS, Imbert P, Moreira C, Niang A, Baujat G, Seye MN, Guyon P: Epidemiology and prognosis of childhood cancers in Dakar, Senegal. Med Trop 2003, 63(4-5):521-526.

12. Israels T, Ribeiro RC, Molyneux EM: Strategies to improve care for children with cancer in Sub-Saharan Africa. Eur J Cancer 2010, 46(11):1960-1966.

13. Howard SC, Metzger ML, Wilimas JA, Quintana Y, Pui CH, Robison LL, Ribeiro RC: Childhood cancer epidemiology in low-income countries. Cancer 2008, 112(3):461-472.

14. Radhakrishnan V, Kashyap S, Pushker N, Sharma S, Pathy S, Mohanti BK, Vishnubhatla S, Ghose S, Bakhshi S: Outcome, pathologic findings, and compliance in orbital retinoblastoma treated with neoadjuvant chemotherapy: a prospective study. Ophthalmology 2012, 119(7):1470-1477.

15. Abdu L, Malami S: Clinicopathological pattern and management of retinoblastoma in Kano, Nigeria. Ann Afr Med 2011, 10(3):214-219.

16. Frikha $H$, Chaari $N$, Nasr C, Bouguila $H$, Chebbi A, Bhouri L, Hentati $D$, Kochbati L, Besbes M, Rifi H, Frikha H, Chaari N, Nasr C, Bouguila H, Chebbi A, Bhouri L, Hentati D, Kochbati L, Besbes M, Rifi H, Oubiche F, Ayed S, Maalej M: Radiotherapy in the treatment of retinoblastoma: about 40 cases. Cancer Radiother 2009, 13(1):30-36.

17. Bowman RJ, Mafwiri M, Luthert P, Luande J, Wood M: Outcome of retinoblastoma in east Africa. Pediatr Blood Cancer 2008, 50(1):160-162.

18. Boubacar T, Fatou S, Fousseyni T, Mariam S, Fatoumata DT, Toumani $S$, Abdoul-Aziz D, Marouf KM: A 30-month prospective study on the treatment of retinoblastoma in the Gabriel Toure Teaching Hospital, Bamako, Mali. Br J Ophthalmol 2010, 94(4):467-469.
19. Wakamb GK, Nkashama GM, Mbuli RL, Borasisi GC, Nikulu Jl: Problematic of the management of childhood cancer: experience of retinoblastoma in Lubumbashi (DR Congo) and the importance of early diagnosis. Pan Afr Med J 2013, 14:64.

20. Nyamori JM, Kimani K, Njuguna MW, Dimaras H: The incidence and distribution of retinoblastoma in Kenya. Br J Ophthalmol 2012, 96(1):141-143.

21. Luo C, Deng YP: Retinoblastoma: concerning its initiation and treatment Int J Ophthalmol 2013, 6(3):397-401

22. Thaddeus S, Maine D: Too far to walk: maternal mortality in context. Soc Sci Med 1994, 38(8):1091-1110.

23. Kagmeni GNF, Monebenimp F, Kouogang G, Ngounou F, Kengne K, Moukouri E: Le Rétinoblastome dans la Région de l'Ouest Cameroun: Aspects Cliniques, Histologiques et Thérapeutiques. Health Sci Dis 2013, 14(2):1-4.

24. Bekibele $\mathrm{CO}$, Ayede Al, Asaolu OO, Brown BJ: Retinoblastoma: the challenges of management in Ibadan, Nigeria. J Pediatr Hematol Oncol 2009, 31(8):552-555.

25. Wessels G, Hesseling PB: Outcome of children treated for cancer in the Republic of Namibia. Med Pediatr Oncol 1996, 27(3):160-164.

26. Ali AA, Elsheikh SM, Elhaj A, Osman N, Abuidris D, Eltayeb EA, Mahgoub M, Hamdoun A, Babiker MM, Mohamedani AA, Ali AA, Elsheikh SM, Elhaj A, Osman N, Abuidris D, Eltayeb EA, Mahgoub M, Hamdoun A, Babiker MM, Mohamedani AA, Elwali NE, Qaddoumi I: Clinical presentation and outcome of retinoblastoma among children treated th the National Cancer Institute (NCl) in Gezira, Sudan: a single Institution experience. Ophthalmic Genet 2011, 32(2):122-125.

27. Nikiema Z, Wenceslas Diallo J, Daboue A, Seydou Traore S, Zorom BT, Bamouni A, Sorgho CL, Cisse R: Trilateral retinoblastoma in Burkina Faso: three cases. Sante 2009, 19(4):185-188.

28. Butros LJ, Abramson DH, Dunkel IJ: Delayed diagnosis of retinoblastoma: analysis of degree, cause, and potential consequences. Pediatrics 2002, 109(3):E45.

29. Reddy SC, Anusya S: Clinical presentation of retinoblastoma in Malaysia: a review of 64 patients. Int J Ophthalmol 2010, 3(1):64-68.

30. Brown BJ, Ajayi SO, Ogun OA, Oladokun RE: Factors influencing time to diagnosis of childhood cancer in Ibadan, Nigeria. Afr Health Sci 2009, 9(4):247-253.

31. Merriam S, Muhamad M: Roles traditional healers play in cancer treatment in Malaysia: implications for health promotion and education. Asian Pac J Cancer Prev 2013, 14(6):3593-3601.

32. Muhamad M, Merriam S, Suhami N: Why breast cancer patients seek traditional healers. Int J Breast Cancer 2012, 2012:689168.

33. Spiegel PB, Checchi F, Colombo S, Paik E: Health-care needs of people affected by conflict: future trends and changing frameworks. Lancet 2010, 375(9711):341-345

34. Sitorus RS, Moll AC, Suhardjono $S$, Simangunsong LS, Riono $P$, Imhof $S$, Volker-Dieben $\mathrm{HJ}$ : The effect of therapy refusal against medical advice in retinoblastoma patients in a setting where treatment delays are common. Ophthalmic Genet 2009, 30(1):31-36

35. Committee on Psychosocial Services to Cancer Patients/Families in a Community Setting Board on Health Care Services: In Cancer Care for the Whole Patient: Meeting Psychosocial Health Needs. Edited by Adler NE, Page AEK. Washington DC: The National Academies Press; 2008.

36. Chantada GL, Qaddoumi I, Canturk S, Khetan V, Ma Z, Kimani K, Yeniad B, Sultan I, Sitorus RS, Tacyildiz N, Chantada GL, Qaddoumi I, Canturk S, Khetan V, Ma Z, Kimani K, Yeniad B, Sultan I, Sitorus RS, Tacyildiz N, Abramson DH: Strategies to manage retinoblastoma in developing countries. Pediatr Blood Cancer 2011, 56(3):341-348.

37. Ashaye A, Ajuwon AJ, Adeoti C: Perception of blindness and blinding eye conditions in rural communities. J Natl Med Assoc 2006, 98(6):887-893.

38. Tunde-Ayinmode MF, Akande TM, Ademola-Popoola DS: Psychological and social adjustment to blindness: understanding from two groups of blind people in llorin, Nigeria. Ann Afr Med 2011, 10(2):155-164.

39. Kumar A, Moulik NR, Mishra RK, Kumar D: Causes, outcome and prevention of abandonment in retinoblastoma in India. Pediatr Blood Cancer 2013, 60(5):771-775.

40. World Health Organization: Social determinants approaches to public health: from concept to practice. Edited by Blas ESJ, Sivasankara Kurup A. Geneva: World Health Organization; 2011.

41. World Health Organization: Cancer Control Knowledge Into Action World Health Organization Guide for Effective Programs: Early Detection. Geneva: World Health Organization; 2007. 
42. Leander C, Fu LC, Pena A, Howard SC, Rodriguez-Galindo C, Wilimas JA, Ribeiro RC, Haik B: Impact of an education program on late diagnosis of retinoblastoma in Honduras. Pediatr Blood Cancer 2007, 49(6):817-819.

43. Spencer $L$, Pagell F, Adams T: Applying the transtheoretical model to cancer screening behavior. Am J Health Behav 2005, 29(1):36-56.

44. Tung WC, Lu M, Cook D: Cervical cancer screening among Taiwanese women: a transtheoretical approach. Oncol Nurs Forum 2010, 37(4):E288-294.

45. Palazzi MA, Stephan C, Brandalise SR, Aguiar Sdos S: Retinoblastoma diagnosis: a proposal based on the experience of centro infantil boldrini, Brazil. Pediatr Hematol Oncol 2013, 30(5):379-385.

46. Prochaska JO, DiClemente CC, Norcross JC: In search of how people change. Applications to addictive behaviors. Am Psychol 1992, 47(9):1102-1114.

47. World Health Organization: Cancer Control Knowledge Into Action World Health Organization Guide for Effective Programs: Diagnosis and Treatment. Geneva: World Health Organzation; 2008.

doi:10.1186/1471-2458-14-944

Cite this article as: Weaver et al: Integrating stages of change models to cast new vision on interventions to improve global retinoblastoma and childhood cancer outcomes. BMC Public Health 2014 14:944.

\section{Submit your next manuscript to BioMed Central and take full advantage of:}

- Convenient online submission

- Thorough peer review

- No space constraints or color figure charges

- Immediate publication on acceptance

- Inclusion in PubMed, CAS, Scopus and Google Scholar

- Research which is freely available for redistribution 